\title{
NEWTON AND THE SCIENCE OF TO-DAY
}

\author{
By SIR JAMES JEANS, O.M., F.R.S.
}

$\mathrm{T}$ HREE hundred years have elapsed since Newton wes born, and 276 since his fertile mind had conceived most of those fundamental ideas, the development of which was to add such lustre to his name and be of such outstanding value to science : in astronomy the idea of universal gravitation; in physics the theory of colours; in mathematics the differential and integral calculus (or, as he would have said, the direct and inverse fluxions) as well as the binomial theorem and the method of infinite series. He tells us he had thought of all these before he was twenty-four years old, although he wrote little about most of them until many years later.

The intervening years have seen Newton's ideas examined, tested and developed as no other set of scientific ideas ever has been, and it might seem that by now we ought to be able to assess his greatness and place him in his rightful position relative not only to the science of to-day, but also to that of all time.

We have no doubts as to his greatness, but we probably feel less confidence in our powers to assess his ultimate position in science than we should have done fifty years ago, and certainly less than his imme. diate successors felt. For they were not content merely to claim outstanding greatness for Newton; they went on to claim a quality of finality and uniqueness which we know better than elaim for him to-day.

Laplace, for example, wrote that the "Principia" was assured for all time of a pre-eminence above all other productions of the human intellect, while Lagrange, after expressing himself in similar terms, went on to say that Newton was "not only the greatest genius that had ever existed, but was also the most fortunate, for, as there is only one universe, it can fall to only one man in the world's history to interpret its laws".

Such eulogies as these are in striking contrast with Newton's own modest estimate of himself. As his life was drawing to its close, he made the much quoted remark that to himself he seemed only like a boy playing on the sea-shore, "and diverting myself," he said, "in now and then finding a smoother pebble or a prettier shell than ordinary, while the great ocean of truth lay all undiscovered before me".

Which of these two estimates, we may ask, is the nearer to the truth? And how far is it possible to reconcile them ? Newton's contemporaries obviously could not have reconciled them. Can we ?

All work in mathematics, no matter how modest it may be, may claim immortality if only it is accurate, since absolute truth can have nothing to fear from the disintegrating influence of time. But it is different with work in astronomy or physics. This must at best be relative to the knowledge, or even to the hypotheses, of its time, so that an increase of knowledge or an abandonment of hypotheses may at any time show it to be of no permanent value. This is as true of the work of Newton as of that of lesser men.

Yet Newton's contemporaries, as well as many generations after them, made the mistake of supposing that Newton's work in astronomy and physics possessed the same sort of absolute validity as his discoveries in mathematics; they thought that no future scientist would ever be able to penetrate to the innermost recesses of Nature's temple and discover more of her fundamental mysteries, because Newton had been there already and had seen all that there was to see. But we of to-day know that Nature's temple has many chambers, room after room, and that Newton had scarcely penetrated farther than the ante-chamber. Our thoughts turn to the work of Planck, Rutherford and Einstein. The ante-chamber which Newton had explored was familiar ground to them, but they found the keys to other, and hitherto unsuspected, rooms; in these they discovered laws every bit as fundamental as any that Newton discovered. We see that Newton was wiser than his contemporaries in his vision of the great ocean of truth which lay all undiscovered before him. But does this add to his intellectual stature or diminish it ? Should it make him seem greater or less in our eyes?

There are some-although mostly laymen in science - who see science primarily as something that is for ever changing. For them the science of any period is like the sand-castles that the children build on the sea-shore; the rising tide will soon wash them away, and leave the sands clear for the new array of castles which will be built the next day. Those who hold such views are led, somewhat naturally, to make such statements as that Newton is out of date and superseded.

But the comparison is obviously faulty. Science is knowledge, and the primary characteristic of knowledge is not that it is for ever changing, but that it is for ever growing. Of course, all growth implies change, so that science must continually changelike the tree which is for ever budding out in new directions-but this is only a secondary effect. The correct comparison is not with sand-castles, which change because they are continually washed away and replaced, but with a vast building which changes as one floor is built on top of another, or a new wing is built where none stood before. This building is not like a medieval cathedral, the creation of a great number of artificers, each building after his own taste and fancy. It is an embodiment of scientific truth, and the truths of science are the same, no matter who discovers them. Whatever artificers build the structure, the blue-prints have previously been drawn by Nature herself, so that, had Newton lived or not, the building must at some time or other have looked pretty much as it looks to-day. And if we are to estimate how much modern science owes to Newton, we must not only consider how much Newton built himself, but also by how much he expedited the building - to what extent, to put it crudely, did Newton act as a catalyst to the growth and consolida. tion of scientific knowledge ?

Let us first consider the significance of Newton's work in pure mathernatics. There have been instances in this subject-especially in the theory of numberswhere a worker has stated a theorem which he believed to be true, but which centuries of discussion have not succeeded in either proving or disproving. Newton's mathematical work was not of that type. His métier was not the discovery of fanciful but comparatively useless theorems in recondite branches of 
pure mathematics, but the forging of practical tools which were urgently needed for further scientific progress, and we may be sure that if Newton had not forged them someone else would have done so in time.

For example, Newton hit upon the binomial theorem in two distinct ways. He, of course, knew the expansions of $(1-x)$ raised to integral powers - squares, cubes, etc. ; these are easily found by simple multiplication. Starting from these known expansions, Newton interpolated to find the values of the coefficients when $1-x$ was raised to intermediate values, such as $\frac{1}{2}, \frac{3}{2}, \frac{5}{2}$.... He also calculated the value of $(1-x)^{1 / 2}$ by taking the square root of $(1-x)$ by the simple rules of schoolboy arithmetic, and of course found that the result confirmed what he had already obtained. It is hard to imagine that such simple artifices could have remained untried for long ; the binomial theorem was simply a nugget lying on the direct road of progress, and it is quite inconceivable that generations of mathematicians could have passed it by without noticing it.

It was much the same with the greater discovery of the method of fluxions. Rouse Ball tells us that, before Newton appeared on the scene at all, the method had been foreshadowed in the writings of no fewer than seven mathematicians-Napier, Kepler, Cavalieri, Pascal, Fermat, Wallis and Barrow. In the more convenient and practical form of the differential calculus, it was actually discovered by Leibniz in 1675, and published to the world in 1684nine years before Newton published his fluxional calculus. Apart from the personal questions involved, the bitter controversy as to whether the two discoveries were entirely independent, or whether Leibniz got ideas from seeing Newton's earlier letters on the subject, seems to me relatively unimportant; the calculus was simply another nugget lying on the direct line of scientific advance, and someone was bound to notice it and pick it up-if not to-day, then to-morrow; if not Newton, then Leibniz.

When we turn to consider Newton's still more famous work in mechanics and astronomy, we find the same story repeated; he did not drag science after him into peculiar paths of his own choosing, but kept to the broad main road, discussing the same problems as others were already discussing. The fundamental ideas with which he worked were not in any way novel, or peculiar to himself. His first law of motion had been given by Descartes in 1644 , and indeed Plutarch had given it fifteen hundred years earlier together with a foreshadowing of the general principles of planetary motions, and the conception of gravity extending as far as the orbit of the moon. In his "De facie in orbe lunae", Plutarch had written, "You fear that the moon may fall, on the grounds that only light air circulates under the moon and that this is not adequate to bear a solid weight. But the moon is secured against falling by her motion and the swing of her revolution-just as objects put in slings are prevented from falling by the circular whirl. For everything is carried along by the motion natural to it, if it is not deflected by anything else."

Much the same, again, may be said about Newton's famous law of gravitation. The attraction of lodestone for iron had familiarized men with the idea that matter could attract other matter across empty space and, so far back as 1600, Gilbert in his "de Magnete" had conjectured that the earth might attract the moon like a magnet. Kepler had gone further in the same direction in 1619 ; we find him insisting on the mutual attraction of all matter, instancing the tendency of all objects to fall towards the centre of the earth, as well as the ocean tides which, he maintained, were caused by the attraction of the moon. He said that two stones out in free space would approach one another, like mutually attracting magnets, and would finally meet at the point which we now call the centre of gravity of the two. He thought that the planets were kept moving in their orbits by some power inherent in the sun, and, although forming a very wrong idea of the nature of this power, he conjectured that it must vary as the inverse square of the distance. However, he immediately abandoned this law in favour of one varying inversely as the simple distance, a change which was challenged by Bouillard, who insisted that the true law must be that of the inverse square. Indeed, one of Kepler's own laws-that connecting the periodic times of the planets with their distance from the sun-shows clearly that the true law cannot be other than the inverse square law. Newton tells us that he had already noticed this in the plague years 1665 and 1666 , but he did not publish it until it had been noticed independently by Hooke, Halley, Huygens and Wren.

Looking back on all this, we can scarcely accept Wordsworth's description of Newton's mind as

"for ever voyaging through strange seas of thought alone."

Except in optics, where he voyaged alone because everyone else had lost the way, Newton's ideas were very much those of his contemporaries. His main achievement was not, as is so often stated, that he was the first to think of gravity as extending to the orbit of the moon, for this had been thought of fifteen hundred years before he was born. Neither was it that he was the first to think of universal gravitation, for many had thought of it before him. Neither was it that he was the first to conjecture that the force of gravitation must fall off as the inverse square of the distance, for this idea was generally current in his time. It was not even that he was the first to understand the general principle of planetary motions, for others understood these equally well.

Newton's great service to science, and through science to the human race, was not that he for ever voyaged through strange seas of thought alone, but that he voyaged through familiar seas of thoughtif not in company with others, at least in seas that were much frequented by others. Bacon had written of his own contributions to scientific thought, that they did not originate in any mental powers of his own, but rather in the spirit of his age"partus temporis potius quam ingenii". It was this same spirit of the age that moulded the form of most of Newton's contributions to science. Scattered scientific ideas-and unproved conjectures in particular-were floating around in abundance, and lesser lights of the firmament had made small, hesitating and uncertain advances in many directions. The age was erying for a man who could systematize, synthesize and extend the whole, and it found him in superlative excellence in Newton. But beyond all this, mental powers such as Bacon had disclaimed for himself were present in overflowing measure in Newton-"qui genus humanum ingenio superavit".

His special talents, as I see them, were : first that, out of a large mass of confused ideas provided largely by others, he was able, with his clear and acute mind, 
unerringly to pick out the true and discard the false; second that, having done this, his amazing mathematical ability enabled him to replace conjecture by proof, and so provide a firm basis from which he could unhesitatingly advance; third that he did advance, with quite incredible speed, sureness and directness, his supreme mathematical ability enabling him to outstrip all competitors with the utmost ease. From conjecturing that a thing is so to knowing that it is so, is usually a very long journey ; it is one which Newton was so often able to take when his competitors were not. For example, Kepler had conjectured that the law of gravitational force might be the law of the inverse square; Newton knew that it could not be anything else. Kepler was so far from certain knowledge that he immediately abandoned this conjecture for another; Newton could not be misled into so doing, because his mathematical investigations provided him with convincing proof of the truth of his ideas. Having once settled his fundamental ideas and feeling full confidence in them, he was able to stride forward into the unknown with sure and rapid steps until he had unravelled almost the whole mystery of the then known universe.

In general it was not in originating ideas but in developing them that Newton's greatness showed itself most outstandingly; he was primarily a synthesist and systematizer. Yet here, as ever when we try to compress his genius into a formula or to map out its boundaries, an exception turns up to suggest that it overflowed all limitations; here it is the optics.

If we wish to understand the fundamental cause of his success, we cannot do better than read what Macaulay wrote in his "History" : "In Isaac Newton two kinds of intellectual power which have little in common, and which are not often found together in a high degree of vigour, but which are nevertheless equally necessary in the most sublime departments of physics, were united as they have never been united before or since. In no other mind have the demonstrative faculty and the inductive faculty coexisted in such supreme excellence and perfect harmony." Einstein delivers a similar judgment even more forcibly: "In one person he combined the experimenter, the theorist, the mechanic and, not least, the artist in exposition. He stands before us, strong, certain and alone: his joy in creation and his minute precision are evident in every word and in every figure." And in truth he was unmatched both in the breadth and depth of his powers. Both contributed to his success. But if anything, the breadth was more in requisition, and so made the greater contribution to the success.

Yet if we are to estimate the extent to which Newton, with his outstanding mental power and unique combination of talents, expedited the growth of soientific knowledge, we cannot but place to the other side of the account his unfortunate habit of keeping his results to himself until they had been discovered independently by someone else. To some extent, this also may be ascribed to the spirit of the age. The seventeenth century had but little of our vision of science as a great benefactor to the human race, or of new knowledge as something which ought to be disclosed at once so as to expedite further progress by others. A man's scientific discoveries were his private property, with which he could do as he liked. Often his ambition was not to enable others to benefit from them, but to prevent others benefiting from them-this is why he would often publish his results in cypher. Or he might regard science, and mathematics in particular, as a sort of mental gymnasium in which contests of skill took place, and competitors issued challenges to one another to determine which of the two was the stronger or quicker. To use Newton's own metaphor, science was, more than to-day, a matter of playing with pebbles on the seashore, and seeing who could find the smoothest pebble or the prettiest shell. Thus there was less feeling of moral responsibility than now, perhaps even less interest in science for its own sake.

So we see Newton's terrifically powerful mind playing with the problems of science like a cat which plays with a mouse and loses all interest when he has killed it, or as we play with a crossword puzzle and regard the incident as finished when we have solved it.

We can see this exemplified in nearly all Newton's major discoveries. He tells us that he had thought of the method of fluxions in the plague year of 1665 . Yet before publishing it even partially (except in cypher) to the world, he allowed twenty-eight years to elapse-years in which Leibniz discovered and published the same thing-and it was not fully published until 1736. Again in this same year of 1665 , Newton satisfied himself that a force of gravity obeying an inverse square law explained the motion of the moon "pretty nearly", and was content to leave it at that. Later, he found that this same law would result in the planets describing the exact orbits they were known actually to describe-ellipses with the sun in one focus. Again he was content to leave it there. Most men would have published this as proof positive of the law of the inverse square, but Newton kept it to himself until Halley travelled to Cambridge to consult him on this very problem. Newton then explained that he had solved the problem five years previously, but had mislaid his proof. Finally, Prof. Andrade has reminded us of the reluctance with which Newton published his "Principia"-probably the greatest single work of the human intellectand of the pressure which had to be applied before he would do so.

Apart from the general secretiveness of his age, we may perhaps find three further causes for this delaying tendency in Newton: an over-active mind which refused to halt by the wayside to perfect and write out results, a disinelination to be satisfied with anything short of perfection, and an extreme sensitive. ness to criticism and consequent desire to avoid controversy, this resulting more than once in a disinclination to pursue the study of science any further. In spite of these handicaps Newton bestrode the scientific world like a Colossus : what would he have been without them ?

Such was the man as I see him; lot us now consider how much of the scientific edifice which Newton built, or was built under his influence, is still in useful service to-day.

Outside pure mathematics, Newton's procedure was simply that of every other true man of science. He started from known facts which, in his judgment, seomed likely to be related-as for example, if legend can be trusted, that apples fall to the ground with an acceleration of 981 c.G.s. units, and that the moon circles round the earth once every $27 \frac{1}{8}$ days-and tried to represent the isolated facts of such a group as special instances of a general system of laws. If this could be done, the set of laws so discovered could be made to predict other phenomena, which could then be submitted to the test of experiment or 
observation. If the laws passed this test, they were assumed to correspond to something in ultimate reality; provisionally at least they were true laws, and showed how Nature worked. If Newton differed from others, it was in the greater range of facts on which he worked.

In any scientific era, the search for such sets of laws is clearly restricted by the range of facts which are known, or are capable of being known, at the time; and we cannot expect scientific men to dis. cover laws of a higher order of accuracy than the observations through which the laws are discovered.

Some may challenge this, arguing that a genius of sufficient stature ought to be able to discover the true reality behind Nature from quite meagre evidence - "ex pede Herculem"- - and that, when this reality was known, the laws governing its behaviour could be deduced and would necessarily be true through. out the whole range of phenomena, whether known or still to be discovered. Unhappily, Nature is not like that. Science can, from the nature of things, never attain to a knowledge of the realities of the world, but only to a knowledge of the phenomena-of the impressions that the world makes on our senses, generally, of course, through instruments of precision. Our sense-organs form a sort of screen on which Nature's lantern is for ever projecting pictures ; we can study these pictures, but can never pass behind the screen to see how the lantern works. As the sequence of pictures thrown on the screen is all that we can ever know or study, a set of laws that links the pictures together in a perfect systematic order is the most that science can provide, or can properly be asked to provide. If meagreness of the instrumental equipment in any age prevents the science of that age from knowing the finer details of the pictures, then we cannot expect the science of the age to provide laws governing these fine details.

For this reason we have to introduce a sort of relativity into our conception of the aims of physics; we may say that the science of any age can aim no higher than at predicting the result of any experiment that can be performed in the age in question. If this is conceded, we may claim that by far the greater part of Newton's work was accurate and final, relative to the age in which he lived; and this part is still of value and still in use to-day.

The enormous increase in instrumental power which has occurred since Newton's time has thrown open new fields for exploration in two directionstowards the infinitely great and towards the infinitely small, from the electron at one end of the scale to the nebulæ and the whole of space at the other. Man and the man-sized world with which Newton was mainly concerned lie about midway between these two extremes.

The laws of Nature are of course universal, so that the same set of laws must prevail throughout the whole of this range, but different aspects of these laws assume importance in turn in different parts of the range. So much is this the case that we may almost regard the different parts of the range as constituting separate and detached worlds in which completely different sets of laws prevail. There is the small-scale world of electrons and of atomic physics in general in which the laws of quantum mechanics prevail, the man-sized world in which the laws of molar mechanics prevail, and the world of the great nebulæ in which the laws of relativity prevail. These three worlds are all governed by the same laws, but factors which are all-important in one become mere insignificant corrections in the others. Newton's work was applicable almost exclusively to the middle-sized world of molar mechanics, and so not in general to the other two worlds, the existence of which was scarcely suspected in his day. Lagrange was wrong in thinking that there was only one universe, and that it could fall to only one man to interpret its laws; there are worlds within worlds, and Newton had only interpreted the laws of one of these. Relative to this world most of Newton's work was accurate and final, which means that it was also accurate and final relative to the age in which he lived.

If we examine any recent paper on theoretical physics, we are likely to find it plentifully sprinkled with either the symbol $h$ or the symbol $c$, or both. These two symbols were unknown to Newton, at least in the sense in which we now use them; they are, so to say, the emblems of the theories of quanta and relativity which did not invade physics until the present century.

The symbol $c$ denotes the velocity of light, which is greater than the velocity of any material object, and is usually enormously greater. Also in dynamical problems the ratio of these two velocities can only enter through its square. We are now familiar with electrons which move almost as fast as light, but the kind of dynamics with which Newton was concerned contemplated no velocity greater than that of the planet Mercury, which is about $48 \mathrm{~km}$. a second. For this, the ratio of the squares of the two velocities is $0 \cdot 0000000256$, or, to seven significant figures, is nil. If we disregard this fraction, the dynamics of relativity becomes absolutely identical with that of Newton, so that to seven significant figures Newton's dynamics was adequate and factually perfect for an age in which nothing moved faster than the planet Mercury.

It is the same with the $h$ of the theory of quanta. This measures the atom of action which Planck discovered in 1899, and although it is of the utmost importance to phenomena on the atomic and subatomic scale, it is absurdly small in comparison with the amounts of action involved in the activities of everyday life. Roughly speaking, the ratio is that of an atom to a gram, or of a gram to a star. This small quantity again was quite negligible in all the problems with which Newton was concerned.

Thus the Newtonian mechanics, dynamics and astronomy were absolutely right factually, except for quantities which were so small that they could not either affect Newton's problerns in any way, or make their existence known through the best instrumental accuracy that was available in his day. To see Newton's work in these subjects in their proper perspective, we must think of him as the builder of the ground floor of the great building of mechanics, dynamics and astronomy, and as its architect for many floors above this. Newton's first and last serious contribution was his "Principia", but after this, floor after floor was added on strictly Newtonian lines: on the dynamical side, the generalized dynamics of Lagrange, Hamilton and Jacobi; on the astronomical side, the dynamical astronomy of Laplace and many others; on the physical side, the electrodynamical theory which we associate primarily with Clerk Maxwell. All this and much more followed the Newtonian architectural plan without any deviation whatever for two centuries. It was not until 1887--just two hundred years after the appearance of the "Principia" - that the Michelson-Morley ex- 
periment first showed that the Newtonian scheme was in actual fact imperfect. But the experiment had to be discussed for eighteen years before this inference was drawn, and it was only when Einstein's restricted theory of relativity appeared that the Newtonian scheme was generally recognized to be inadequate.

It is, however, inadequate only with reference to the ultra-refinements of modern science. When the astronomer wishes to prepare his "Nautical Almanac", or to discuss the motions of the planets, he uses the Newtonian scheme almost exclusively. The engineer who is building a bridge or a ship or a locomotive does precisely what he would have done had Newton's scheme never been proved inadequate. The same is true of the electrical engineer, whether he is mend. ing a telephone or designing a power-station. The science of everyday life is still wholly Newtonian; and it is impossible to estimate how much this science owes to Newton's clear and penetrating mind having set it on the right road, and this so firmly and convineingly that none who understood his methods could doubt their rightness. Without his guidance, smaller men might have argued for centuries as to what was right and what was wrong. When Newton had spoken, it soon came to be recognized that the time for controversy as to which was the right road was past; it only remained to advance along the Newtonian road.

Newton's work in optics stands somewhat apart from the rest, in that he was much less indebted to his predecessors and contemporaries. Indeed, current ideas on the nature of light were so vague and erroneous that he was probably hindered rather than helped by what he knew of them, and was perhaps fortunate in not knowing more. We know that he attended the lectures of Barrow in Cambridge, where he would doubtless become acquainted with the optical theories of Descartes as well as with those of Barrow himself. Now Descartes thought that all space was filled with substance, and that vision resulted from the transmission of a pressure from one particle to another of this substance-much as a blind man pokes about with a stick. He thought that different sensations of colour resulted from the particles rotating with different speeds, red resulting from the most rapid rotations, and yellow, green and blue following in this order. Barrow held even more fantastic opinions; he thought that red light was more concentrated than light of other colours, but was broken up by intervals of complete darkness, yellow light consisted of a mixture of this red light with white, and so on. Hooke conjectured that light consists of a rapid vibrational motion of an ethereal medium filling all space, different colours being produced by different shapes of wave; blue, for ex. ample, resulted from "an oblique and confused pulse of light".

Into the midst of all this confusion of thought came Newton, to whom, in Einstein's words, "Nature was an open book, whose letters he could read without effort. The conceptions which he used to reduce the material of experience to order seemed to flow spontaneously from experience itself, from the beautiful experiments which he arranged in order like playthings." With the prism he had bought at Stourbridge Fair, he went at once to the crucial experiment of the spectrum. Finding that this was longer than it was broad, he at once saw that differences of colour must result from different degrees of refrangibility. This discovery alone, the subject of Newton's first scientific paper, published in our
Phil. Trans, of 1672, at once took the theory of light leagues beyond the point to which any previous investigator had brought it, and opened the road to further rapid progress.

But Newton brought his views into discredit in the eyes of many by appearing to think of light as a material substance-Hooke definitely brought this charge against him. Actually Newton repeatedly claimed that his results did not depend on any special views as to the ultimate nature of light, and he was careful to avoid such words as 'corpuscles' which might seem to imply such views. Yet much of his thought seems to become meaningless unless we identify his rays-the "least parts" of light-with something of a corpuscular nature. However little he may have said about it, Newton seems always to have had his own picture of the structure of light before his eyes, and this picture was corpuscular.

For two centuries many thought of this as the one serious mistake that Newton ever made. Recently the pendulum has swung-perhaps too far-in the other direction. Light is a transfer of energy from matter at one place to matter at another, and this transfer can only take place by complete units, or 'quanta'. This led Einstein to picture light as a shower of arrows, each arrow containing a single complete quantum of energy, and some have hailed Newton's corpuscular theory of light as a brilliant prevision of this.

But we must remember that Newton introduced his corpuscles primarily to explain the rectilinear propagation of light, whereas Einstein introduced his light-arrows to pieture the quite different property of atomicity. This being so, the similarity of the two pictures can scarcely be quoted as a supreme example of intuition on the part of Newton. It might be if light really did consist of corpuscles; Newton would then have arrived at the truth by one road two hundred years before Einstein reached it by another. But no competent physicist can for a moment suppose that light consists either of corpuscles or of light-arrows; these are only pictures we draw for ourselves to help us understand parts of a truth which we know, as a whole, to be for ever beyond our comprehension.

At this point we are inevitably brought to consider Newton as a philosopher. Unlike his great predecessor Descartes and his great contemporary Leibniz, he seems to have had very little interest in philosophy for its own sake. He was what we might describe to-day as a pragmatist; his main concern with a philosophy was not as to whether it was true, but whether it worked and yielded useful results. It was another illustration of the ever-recurring difference between the British and the Continentals.

Descartes had taught mathematicians to measure co-ordinates from fixed lines on a piece of paper. Newton wanted to be able to measure mechanical and astronomical co-ordinates in the same way from positions in space and instants in time. So he assumed without further ado that time could be measured from a fixed standard instant, and that the remotest parts of the universe contained vast immovable masses, providing standard positions against which absolute motion could be measured.

This assumption of the existence of absolute time and space was a mere working hypothesis which, as he admitted, might not be true at all : "it may be that there is no body really at rest, to which the places and motions of other bodies can be referred". But the assumption, whether true or false, produced 
results-nothing less than a consistent scheme which explained a large part of the then known workings of Nature. This being so, philosophers such as Bruno and Leibniz might argue in vain that absolute space, time and motion were meaningless and illogical.

It was much the same in mechanics. In the mansized world of seventeenth-century science, motion was the result of pushes or pulls of the kind that a horse exerts on a cart. Other suggested causes of motion, such as action at a distance, were regarded much as we of to-day regard levitation or tableturning, and described as "occult qualities". It was inevitable that Newton's force of gravity should come under this description. Leibniz wrote, "Some men begin to revive, under the specious name of forces, the occult qualities of scholasticism, but they bring us back again into the Kingdom of Darkness". Newton's reply was a fine defence of his pragmatical philosophy. To understand the motions of the planets under gravity, he says, even though we do not know the cause of gravity, is as good progress in philosophy as is a knowledge of the motions of the wheels of a clock in the philosophy of clockwork, even though we do not understand why the weight which moves the wheels falls earthward.

At the same time, he refused to admit that his gravitational forces were not wholly mechanical. From the celestial phenomena, he said, we calculate the force of gravity with which bodies are drawn to the sun and the several planets. Once having found these, we deduce the motions of the planets, the comets, the moon and the sun, and "I wish we could derive the rest of the phenomena of Nature by the same kind of reasoning from mechanical principles".

It is interesting to speculate as to what might have happened if Newton had shared the views of Leibniz as to the relativity of all motion. It is conceivable that he might have arrived speedily at what we now call the restricted theory of relativity, that through it he would have seen the impossibility of action at a distance, and would then have developed a relativity theory of gravitation similar to that of Einstein. It is conceivable, but I can scarcely think it would have happened-the necessary physical ideas and mathematical technique seem to be centuries removed from the fields in which Newton worked. It is more likely that he would have been compelled to come down to an approximation which would have brought him back to the Newtonian mechanies and the inverse square law. If so, his erroneous philosophical background of absolute space and time was a real advantage, since it provided him with a short cut to a region which would have had to be explored anyhow as a preliminary to further progress. It enabled him to go direct to the main point as it appeared in the seventeenth century, neither hindered by any philosophical subtleties nor haunted by any fears that his system might not be an expression of final absolute truth.

In this way Newton created a system which, although philosophically unsound, was destined to endure for two centuries before any chinks were found in its armour. Then more philosophically minded Continentals had to be called in to patch up the deficiencies.

In this quality of practical and opportunist directness, as in many others, Newton seems to me to be typically British. In general he excelled where the British excel, and was weakest where the British are weak. If we think of his various pre-eminences in turn, and consider who runs him closest in each, we shall find it is usually a British man of science who comes to mind. If we try to match the simple directness and the clear logical sequence of his experiments in optics, our thoughts turn to our own Faraday and Rutherford. Clerk Maxwell runs second to him, I think, in other aspects of his work. But if we think of those who excelled him in his philosophical outlook, we have to think exclusively of Continentals, from Leibniz on. His successes were typically British, and his failures-in so far as he ever failed-were also typically British. We can not only be proud that this greatest of all scientific men was our own countryman, but we may reflect with satisfaction that he was no freak genius or sport, but was the concentrated embodiment of all the distinguishing characteristics of British science. 